\title{
Influence of the Psychological Capital and Perceived Organizational Support on Subjective Career Success: The Mediating Role of Women's Career Adaptability in the Saudi Context
}

\author{
Mona Mohamed Sayed Ibrahim ${ }^{1} \&$ Amina Ahmed Amari ${ }^{2}$ \\ ${ }^{1}$ Faculty of Commerce, Mansoura University, Egypt \\ ${ }^{2}$ Faculty of Economics and Management, Nabeul University, Tunisia \\ ${ }^{1,2}$ Faculty of Economics and Administrative Sciences, Imam Muhammad Ibn Saud Islamic University, KSA \\ Correspondence: Mona Mohamed Sayed Ibrahim, Faculty of Commerce, Mansoura University, Egypt. E-mail: \\ monaib2071@yahoo.com
}

Received: June 1, 2018

Accepted: July 22, 2018

Online Published: August 2, 2018

doi:10.5539/ijbm.v13n9p189

URL: https://doi.org/10.5539/ijbm.v13n9p189

\begin{abstract}
This paper is the first to explore predictors' keys of career adaptability and subjective career success in the Saudi context. Many employees, especially women, are facing several challenges in their work, and career adaptability is a way to overcome these difficulties to reach the career success. This research investigated the mediating role of career adaptability (CA) in the relation between both psychological capital (PsCap) and perceived organizational support (POS), as predictors of CA, and subjective career success (SCS). To test our hypotheses, we collected survey data from academic staff in Saudi universities in Riyadh. The results revealed a significant relation between both (PsyCap) and POS on CA. This relation also influenced the SCS through a partial mediation of CA.
\end{abstract}

Keywords: career adaptability, subjective career success, psychological capital, perceived organizational support

\section{Introduction}

The concept of "life designing" means that workers must take care of one's career. During the recent years, many socio-economic upheavals have marked the organizations: the contents of the jobs are in constant evolution and require permanent competencies improvement. Consequently, employees have to survive in uncertain situations in order to and be employable and guarantee their position within the organizations (Savickas, 2005). In the same line of ideas, Ito and Brotheridge (2005) affirm that workers are called to become more career-resilient and engaged in career development activities to deal with changes in the required knowledge, skills and abilities, and facilitate their mobility. Career management is then no longer the responsibility of the company, but rather the individual. Each employee must demonstrate autonomy and take charge of one's career in order to achieve his goals.

The concept of career adaptability (CA) has emerged in this context to determine the factors of career success (CS). Initially, CA was presented as a theoretical construct to conceptualize how the individual deals with or adapts to the challenges of an evolving world of work (Super \& Knasel, 1981). Later, CA is assimilated to "a psychosocial construct" which shows the disposition individual's resources to cope with current professional development tasks, professional transitions and personal trauma (Savickas, 2005). Despite the fact that the CA is considered as fruitful field, this relatively "new concept" (Karatepe \& Olugbade, 2017) remains "elusive" since it's not well defined and has received little attention in the current empirical researches. Then, CA deserves to be more investigated to determine their antecedents and consequences (Karatepe \& Olugbade, 2017) since fewer studies have worked on it (Zacher, 2015; Bocciardi et al., 2017; Karatepe \& Olugbade 2017). Almost all of these studies have been carried out in Western countries (Buyukgoze-Kavas, 2016) such as China, South Korea, South Africa, United States, Belgium and Switzerland (Savickas \& Porfeli, 2012). In addition, only, few researchers have invested in the study of professional success in the Middle East and studies devoted to the women' CS are rare too (Tlaiss, 2015; McMahon et al., 2012). Thus, a study on the women CA in Saudi Arabia will lead to build up a new lighting on what the $\mathrm{CA}$ is. 


\section{Career Adaptability}

The turbulent economic conditions that have marked the organizations over the past two decades, such as the increase in the unemployment rate, massive use of precarious jobs and underemployment, have led to a major disruption of work. On another side, the new approach to career assessment must challenge the traditional conception of work marked by the stability of working conditions (Chong \& Leong, 2017) where individuals do not care much about their careers and their future as long as employment is quasi-guaranteed. Hence, it's important to concentrate on CA, which allows adaptation with the flexibility required by changed labor markets (McMahon et al., 2012). Savickas (1997) is one of the first who proposed the CA theory. According to him, CA can be defined as "readiness to cope with the predictable tasks of preparing for and participating in the work role and with the unpredictable adjustments prompted by changes in work and working conditions". Other authors defined the CA as a psycho-social construct to know how individuals will implement their resources in order to cope with the current potential demands of their jobs and to able to avoid dramatic personal situations (Ferreira, 2012; Guan et al., 2014; Ismail et al., 2016; Öncel, 2014; Savickas, 2012). CA also concerned the tasks in perpetual transitions and disturbances (Bocciardi et al., 2017). Consistent with these definitions, CA has been conceptualized as a self-regulation, malleable competency, rather than a stable personality trait (Rudolph et al., 2017; Savickas \& Porfeli, 2012; Chong and Leong 2017; Jiang et al., 2018). The career theory focuses on the necessity for continuous adjustment allowing development and diffusion of self-concepts at all levels of work to achieve professional success and satisfaction (Karatepe \& Olugbade, 2017). Chong and Leong (2017) affirmed that workers who cannot ensure CA may find themselves in career maladjustment situations.

According to Savickas $(2013 ; 2005$; 1997), the CA is a psychological construct set which contains four explanatory resources, called also the four ' $\mathrm{C}$ ': concern, control, curiosity and confidence:

- $\quad$ Concern: designs how much the employee is attentive to his career goals. He must be planful to achieve them taking into account his environment.

- $\quad$ Control: reflects how much the employee is decisive to manage his environment by developing a self-control regulation strategy. He must be able to understand and control the decisive factors for success of his professional projects.

- $\quad$ Curiosity: designs how much the employee is an explorer to discover himself and the external world. The employee is considered as an actor in the change who need to identify new "selves" to cope with uncertain professional context and should be really empowered to manage his career by himself. Concretely, he must seize the career opportunities offered to him.

- $\quad$ Confidence: reflects how much the employee solves the problem despite the challenges. He must make sure of his own abilities to solve the problems that he will face during his career.

Every worker is supposed to have these CA resources needed to manage a number of challenges and difficulties and reach CS (Karatepe \& Olugbade, 2017). More explicitly, individuals must own these four self-regulatory resources to develop adaptive solutions in a context of complexity and unfamiliarity with respect to career transitions, unplanned events and barriers (Maggiori et al., 2013; Savickas \& Porfeli, 2012; Tolentino et al., 2014; Zacher, 2014). In the same perspective, many researchers have characterized CA as a set of resources in transaction (i.e. attitudes, competencies and behaviors) which create environmental harmony and allow positive immersion in one's work (Klehe et al., 2011; Coetzee et al., 2017). Indeed, CA's resources have to be malleable and not fixed factors because they are able to evolve in any context, at any moment of the person's life (Savickas \& Porfeli, 2012; Koen et al., 2012).

Gosch and Fouad (2017) noted that gender is significantly related to CA, as woman are more adaptable than men, since they are managing better than men the several constraints that they are facing. Some researchers have looked for factors that can alter women's CA, in the 90s, the notion of Glass Ceiling (GC), which dominated the literature in management, is still being considered as the most adapted metaphors to examine inequalities between men and women in the workplace (Pigeyre \& Valette, 2004; Bombuwela \& De Alwis, 2013). It refers to a different kind of obstacles such as (cultural, organizational, family, etc.) that prevent women from leadership or gaining any high positions. According to Bombuwela and De Alwis (2013), the GC may impact on women's career through many factors such as individual (lack of self-confidence), organizational, cultural and family factors (child care). These authors concluded in their research done in Sri Lanka, that individual barriers are the most significant factors creating GC whereas cultural barriers and organizational barriers are the second and third most significant factors. Although these barriers are visible (glasses), the management is disarmed to limit them. Women are not safe from stereotypes about their abilities and organizational performance: professionally, they are known to be less combative and less ambitious than men (Pigeyre \& Valette, 2004). In other hand, the 
influence of the organizational context can be heavy: decision-makers tend to dismiss women from positions of responsibility. Women are given tasks with less power and responsibilities (Pigeyre \& Valette, 2004) because they are judged to be often unavailable and therefore less likely to gain experience in management. Consequently, women's CA will dive into a vicious circle: because lack of experience, they will have less chance to evolve in their career than men.

As conclusion, women are torn between their professional goals and personal goals. They have to make concessions every day to consulate between their job and family. This assumes that the woman must be emotionally and cognitively armed to maintain her CA in these two paradoxical environments.

\section{The Conceptual Model and Hypotheses}

To improve our understanding of career adaptability's role, our paper aims to test a model linking psychological capital, perceived organizational support, career adaptability, and career success.

\subsection{Subjective Career Success as Outcome of CA}

In the next paragraphs we will present what subjective career success is and undermine its relation with CA.

\subsubsection{Lighting on Subjective Career Success}

Career success is a dual concept: objective and subjective (Cenciotti et al., 2016; Pan \& Zhou, 2015). Objective career success (OCS) refers to financial and verifiable aspects of the career and is evaluable by a third party (Hall and Chandeler, 2005). It focuses on objective criteria such as salary growth or promotion, which are now less and less adapted to current organizations and employee attitudes (Shockley et al., 2015).

More recently, some researchers have taken a close interest in subjective career success (SCS) and emphasized on the important role of "non-objective" factors in career success (Shockley et al., 2015). The concept of SCS is inherent to the person himself: it depends heavily on the self-judgments of the person. For some authors, SCS refers to the individual's feeling of being satisfied with his or her own career (Cenciotti et al., 2016; Pan \& Zhou, 2015). For others, it refers to the interpretation that the individual makes of his success (Hall and Chandler, 2005). Globally, Pan and Zhou (2015) noted that SCS refers to employees' perceptions of how they achieved their career goals based on past career experiences, and how they anticipated their future career goals based on personal criteria. These definitions provide only a few aspects of SCS because it's more complex compared to OCS (Pan and Zhou, 2015). Then, it seems difficult to draw perfect borders of SCS, which remains a relatively vague concept (Shockley et al., 2015) as it is at the crossroads of several notions such as career performance and job satisfaction.

In fact, and according to some authors, SCS is a different concept compared to job satisfaction because career success lasts longer than satisfaction (Tremblay et al., 2014; 2009). First, they explain that the success is an employee's assessment of the development of a dynamic career, whereas satisfaction is an immediate reaction of the employee to a static career. Second, a satisfactory work with few future career prospects does not necessarily lead to SCS because when the results obtained from previous careers are inconclusive, the employee will no more persevere to reach the success. Finally, SCS is more personalized than career satisfaction (Pan \& Zhou, 2015) because success is an assessment of prefixed work objectives, while satisfaction is judged by if the current situation is acceptable. For example, an individual positively appreciated by his hierarchy, will benefit from a promotion as a reward but he will not necessarily be satisfied in his future career. This satisfaction comes from within the individual and his intrinsic motivation. In other words, the individual who positively perceives changes in his career will be more satisfied. Consequently, this individual will make sure to seize the opportunities offered to him, meet the challenges and develop potential skills to adapt with this new career change. While, the more the perception of his career change is negative, despite the advantages that it may contains, the less he will feel satisfied.

\subsubsection{CA and the SCS}

SCS is related to different antecedents (Zhou et al., 2013; Cenciotti et al., 2016) but little empirical studies lead to the existence of positive impact of CA on SCS. Some authors put forward the relationship between career satisfaction and career performance (Zacher, 2014), others underline the link between satisfaction and promotability (Tolentino et al., 2013) while, other authors focus on the job search self-efficacy and on salary (Guan et al., 2013). Savickas (2013) concluded that individuals who are willing to adapt are more likely to generate options and achieve career goals.

Depending on these studies, we expect that the more CA is important, the greater the CS will be. However, we think that these studies turn out to be limited by the complexity of both CA and SCS. For this reason, it seems 
important to focus more on the consequences of CA in the hope of bringing new results in Saudi Arabia context. Thus, we formulate the following hypothesis.

\section{Hypothesis 1: CA has a significantly positive influence on SCS.}

\subsection{Antecedents of Career Adaptability and Subjective Career Success}

In what follows, we will present the Psychosocial Capital and Perceived Organizational Support which retained as antecedents of both CA and SCS.

\subsubsection{Psychological Capital}

The concept of Psychological Capital (PsyCap) has been advanced and developed by Luthans in 2002. Luthans's researches are the ones that have more influence on the theory of PsyCap (Sarwar et al., 2017). The PsyCap is a continuum with other capitals, such as human capital "what you are" and social capital "who you know". Briefly, the PsyCap can be understood as "who you are" and "what you can" at the same time (Sarwar et al., 2017). Following Seeligman's principals (2002), Luthans (2002) highlights the importance of studying the positive organizational behaviors, defined as applying the strengths of the positive human resource and positive psychic abilities that can be measured, developed and effectively managed to improve the individuals' performance. The author adds that positive psychological aspects focus on ideal human functions.

According to Luthans et al. (2007), the PsyCap contains a set of positive psychological capacities described by four dimensions summarized in the acronym "H.E.R.O" (Levene, 2015): hope, self-efficacy, resilience and optimism.

Hope is defined as an individual's perception of his or her own abilities to infer paths and means that leads to desired goals and motivate the individual through the energy of purpose-oriented thinking (Snyder, 2002). It's also refers to maintain goals and adjust paths - if necessary - for success and considered as an important element of PsyCap mandatory in our daily life (Sarwar et al., 2017). Individuals, who have hope, are often stimulated by their sense of having the ability to develop ways to reach what they wish to achieve. Hope also gives them the possibility to create alternative paths since they are facing impediments (Luthans \& Youssef, 2004; Snyder \& Lopez, 2002). Aware of the personal, cultural and family issues surrounding them, women cannot achieve their career goals in the short term despite their hope and optimism. They are lead to define priorities in their goals to manage them efficiently.

Self-Efficacy was first introduced by Bandura (1997) and defined as the confidence of individuals in their ability to mobilize their resources of knowledge, behaviors and methods required to carry out a specific task successfully in a particular environment (Luthans \& Youssef, 2004). It also refers to the confidence to make the necessary efforts to succeed within challenging tasks (Sarwar et al., 2017; Larsen \& Luthans, 2006). Individuals with high self-efficacy develop additional efforts and persevere against the adversities that they are facing (Larsen \& Luthans, 2006). So, the management must think carefully about their abilities before selecting and initiating any set of actions. Following these ideas, self-efficacy can be considerate as factor of CA significantly related to the performance (Sarwar et al., 2017).

Women usually tend to underestimate their own efforts and postpone career goals because they are aware of their inability to achieve them in the immediate future as long as they have other priorities. That's why they may have a moderate self-efficacy.

Resilience, the third component of PsyCap is defined by Luthans (2002) as positive psychological abilities to recover against obstacles, uncertainty, conflict, failure and even positive changes like individual progress and increased responsibilities. In the same perspective, Norman (2006) characterizes resilience as a positive response either to negative events or positive events that can generate negative reactions by the individual, as well as increased stress. When individuals or groups encounter constraints during the accomplishment of their tasks then overcome this situation quickly and effectively is the product of resiliency (Clapp-Smith et al., 2009). It is also a response to events, especially disability, rather than event making. Resilient individuals tend to be more efficient in various life experiences, take risks and overcome difficulties (Sarwar et al., 2017). This allows the development of multiple life experiences under circumstances where they may be threatened (Coutu, 2002). So, high resilient people are those who avec the ability to take risk and overcome difficulties (Sarwar et al.2017).

Women are facing many challenges that can be often paradoxical: being a super woman and professional in the same time. That's why women's career management requires a step back to recognize their professional strengths, assess their motivation's level and seize the opportunities in their work to manage their careers with success. So, women can have an important resilience capacity because they can demonstrate flexibility to overcome these challenges in order to create a balanced status in their work and entourage. 
Optimism is defined as an activity related to the achieving goals and self-regulation (Sarwar et al., 2017) and it can be described by the positive interpretive pattern of the individual. It refers to taking a positive look at current and future results (Cenciotti et al., 2016). Optimistic individuals tend to make positive events as a result of subjective factors, while negative events result from external factors and act as temporary events (Carver \& Scheier, 2003). Optimistic individuals expect also good things to happen, which in turn will have important behavioral and cognitive implications. It is important to note that PsyCap takes into account the value of optimism associated with positive outcomes and includes positive motivations and emotions while remaining realistic (Luthans, 2002a).

In a masculine culture like that of Saudi Arabia (Hofstede, 2017), women miss autonomy that could reduce their optimism and career ambitions. As a result, some career paths are fairly stable for women, especially if they work in the public sector.

As a conclusion, a woman has several strengths and positive attitudes but she can be different from men because she meets more constraints. The more she is confronted to challenges, the more important and positive PsyCap is.

\subsubsection{Psychological Capital as a Predictor of CA}

A few studies focused on determining the effect of the Positive workers' psychological traits on CA. For example, a study of Buyukgoze-Kavas (2016), was applied to a sample of undergraduate students, studied three of PsyCap components: resilience, hope and optimism as potential predictors of CA. This author believes that academic years are essential for CA because during this time, students make important decisions for their future employment. In the other hand, Hirschi (2014) has noted that hope is an essential psychological resource linked to positive human development in various areas of life. The result of his empirical study found that hope is needed by both students and professionals to develop attitudes through career development (i.e., career planning, decidedness, and self-efficacy beliefs). More globally, Chen (2013) found that PsyCap components accurately predict one's perceived capacity and interest, and they are considered as proactive career behavior antecedent. Chong and Leong (2017) affirmed that personality traits and skills are fundamental because they enable researchers, professionals and organizations to anticipate individuals' CA. However, Luthans uses the "state" concept rather than "traits" to underline that PsyCap's resources (already presented above) are far to be stable (Luthans et al., 2007). The same idea is shared by Sarwar et al. (2017) who affirmed that these dimensions are characterized by a "state-like" and are likely to evolve.

In this study, we assumed that dimensions of psychological capital have significant positive impact on CA (H2). So, the following hypotheses are drawn:

Hypothesis 2a: Hope has a significantly positive influence on $C A$.

Hypothesis $2 \boldsymbol{b}$ : Self-efficacy has a significantly positive influence on CA.

Hypothesis 2c: Resilience has a significantly positive influence on CA.

Hypothesis 2d: Optimism has a significantly positive influence on $C A$.

\subsubsection{Psychological Capital as a Predictor of SCS}

Career success is considered as dynamic concept that can change over time (Pan and Zhou, 2015). So, individuals have to be a proactive "malleable state" (Luthans and Youssef, 2007) and are called to develop behavior and skills to adapt to new job requirements. SCS is considered as the psychological success that can be studied in several ways, which is dependent on individual's traits to reach a successful career (Tremblay et al., 2009; Seligman, 2002).

Recently, research has put forward the positive effect of PsyCap on many employees' attitudes and behaviors such as organizational commitment, professional engagement, and subjective well-being (Singhal and Rastogi, 2018; Peterson et al., 2011; Avey et al., 2010). According to Luthans and Youssef (2004), the four dimensions of PsyCap impact organizational performance. They affirmed that each one of these criteria is positive, unique, developable, measurable and performance-related. Luthans and Youssef (2007) showed that positive PsyCap reflects positive psychological situations that enhance organizational effectiveness. Furthermore, the four basic concepts of PsyCap help to improve performance effectively and impact the professional success (Luthans et al., 2007; Peterson et al., 2011).

Individuals with high hopes will have more energy to manage the pressure successfully; those who have great resilience will have the ability to overcome the adversity and uncertainty. Finally, the optimists and those with self-efficacy will be able to overcome obstacles and they will succeed and guarantee their career paths. PsyCap is observed as an important contribution for achieving positive results to improve work performance and human 
resources (Luthans et al., 2008). The concept of PsyCap can be presented also as one of the main concepts of positive organizational behavior which contributes to the competitive advantage of the organization (Sarwar et al., 2017; Luthans et al., 2004; Luthans et al., 2008). Indeed, each individual is interested to have a positive psychological state in order to assume the new requirements of his future employment to guarantee a better job satisfaction and career success.

However, Cenciotti et al. (2017) has shown that the direct impact of the PsyCap on professional success has not been adequately studied and affirmed that the empirical results have concluded that PsyCap has positive effects on job satisfaction which is an indicator of SCS among others (Luthans et al., 2010; Kaplan \& Bíckes, 2013).

At a given moment, the individual is called to make the point of his career. He will evaluate the overall of his past achievements and that determines his current career goals so that they can be implemented in the future. This assumes that each individual will have to develop action plans based on positive (PsyCap) to guarantee his self-satisfaction at work. The PsyCap plays an important role in ensuring the SCS. The more these components of PsyCap are favorable, the more SCS will be completed. Following this idea, the PsyCap appears as a determinant factor of SCS and we suppose the existence of a link between PsyCap and SCS. So, we emit the following main hypothesis (H3): Psychological capital has a significantly positive impact on SCS.

Hypothesis 3a: Hope has a significantly positive influence on SCS.

Hypothesis 3b: Self-efficacy has a significantly positive influence on SCS.

Hypothesis 3c: Resilience has a significantly positive influence on SCS.

Hypothesis 3d: Optimism has a significantly positive influence on SCS.

\subsubsection{CA as a Mediator between PsyCa and SCS}

We have shown above that the PsyCap influence on CA (Buyukgoze-Kavas, 2016; Hirischi, 2014) while knowing that the $\mathrm{CA}$ includes four indicators (concern, confidence, control and curiosity) (Savickas and Porfeli, 2012). On the other hand, we underlined also that CA impacts positively on SCS by developing proactive competencies (Karatepe \& Olugbade, 2017; Boccardi et al., 2017). Nevertheless, and according to our knowledge, few studies have shown the relationship between PsyCap and SCS which is mediated by some variables. For example, Cenciotti et al. (2017) concluded that job crafting totally mediated the effect of PsyCap on career success.

The lack of empirical results led us to reflect on the mediating role of CA between the relation of PsyCap (hope, self-efficacy, resilience and optimism) and SCS and in Saudi Arabian context. However, only few studies have highlighted that CA plays a mediating role in the effect of some variables on SCS. For example, Spurk et al. (2013) noted that career adaptability appeared as an important mediator between the Proactive Personality and Career Success. In our paper, we suppose that CA could be a mediator between PsyCap and SCS. Then, CA is a set of abilities resulting from a positive PscCap that enable individuals to adapt to new work situations to reach their Career Success. We present the fourth hypothesis: H4: PsyCap indirectly influences CS through the mediation of $\boldsymbol{C A}$. Thus, from this main hypothesis (H4), we deduced the following hypotheses:

Hypothesis 4a: Hope indirectly influences CS through the mediation of CA.

Hypothesis 4b: Self-efficacy indirectly influences CS through the mediation of CA.

Hypothesis 4c: Resilience indirectly influences CS through the mediation of CA.

Hypothesis 4d: Optimism indirectly influences CS through the mediation of CA.

\subsubsection{Perceived Organizational Support}

Current trends are at the origin of new forms pairing of work organization that have deeply marked the content of jobs in the organization. Now, careers are unstable and therefore, individuals are called to be vigilant and take in charge their careers by developing new attitudes, behaviors and skills, all in adequacy with the new expectations of their work. The more the individual is concerned with career challenges, the better he will develop proactive skills to preserve his employability. By proactive skills, we mean the set of skills that enable the worker to cope with future situations. Social support falls within the field of social psychology and integrated work psychology and human resources management in the late 1970s with the work of LaRocco et al. (1989) to test the direct effects of social support on work quality.

The organizational support theory (OST) has attracted the attention of several researchers because the relationship between employee and organization has a potential value from the employees' point of view (Barrera et al., 1981; Eisenberger et al., 1986; Pierce et al., 1996). 
The Perceived Organizational Support (POS) is considered as a support received from both the supervisor and coworkers (Yang et al., 2015; Kurtessis et al., 2015; Hämmig, 2017) and refers to how individuals evaluate the help given by his professional entourage. These aids can be both intangible (advice, listening, interpersonal exchange) and tangible (financial loans, leave, etc.). POS is also what people think about the extent of their contributions and how much the organization cares about their well-being (Kurtessis et al., 2015). Reciprocally, the organization is interested by the POS as an indicator enabling it to assess the degree of individuals' commitment. POS refers to how individuals evaluate the help given by their professional entourage. A positive POS is manifested by a strong commitment of individuals who feel beholden to the organization and persevere to achieve organizational performance. The employee, who notices that his organization takes his expectations into account, will do more efforts to achieve his goals (Eisenberger et al., 1986).

\subsubsection{Perceived Organizational Support as a Predictor of CA}

The relationship between POS and CA remains unclear as empirical research implementing it is rare, this situation hinders the understanding of how to develop CA and use it pertinently to achieve professional goals (Chong \& Leong, 2017; Karatepe \& Olugbade, 2017).

In the beginning, some authors spoke about the "work environment" as a factor of CA and agree that CA does not only depend on personnel skills, but also on the characteristics of work environment (Boccardi et al., 2017) in which the employee evolves. According to the Individual Career Adaptability (IAC) theory, the vocational environment appears as a key factor determining CA, individual must have flexible skills enabling them to change and adapt to many several tasks or environments, especially the dynamic environment which requires adaptive behaviors, proactive personality and entrepreneurial abilities (Ployhart \& Bliese, 2006).

After, Chong and Leong (2017) noted that the "environmental exploration" is positively linked to CA, which required the search for new information on jobs, professions and organizations. These authors added that CA results from an interaction between individuals and their environments, where individuals engage in a "sense-making" procedure and will be able to assess their interests, skills and career opportunities offered by their work (Chong \& Leong, 2017).

Recently, some studies have focused on the work social support as a predictor of CA (Ito \& Brotheridge, 2005; Yang et al., 2015). According to Karatepe and Olugbade (2017), the social support received at the workplace is a prerequisite condition for people with changing professional roles and who have to deal with careers transitions. In addition, a supportive environment, based on good interpersonal relationship, is considered as a vector for social adjustment (Saks \& Gruman, 2011) and contributes to emotional results such as career satisfaction and intention to stay in the organization.

When employees find both instrumental and emotional support from their supervisors and colleagues (Karatepe \& Olugbade, 2017), they will feel more confident in managing the difficulties and more satisfied with their careers and less likely to leave the actual organization. Ito and Brotheridge (2005) argued that participation in decision-making and autonomy as well as career support received from supervisors (information, advice, and encouragement), stimulate CA. Yang et al. (2015) reached the same conclusion, and specified that colleagues' support has positive impact on individuals who enjoy their work environment and excel in their jobs by performing better than those with less support.

Ultimately, we think that POS is linked to CA. When an employee receives assistance from their colleagues and supervisors this may help them to deploy their efforts and behaviors in order to foster their adaptability. Depending on these studies, the following hypothesis is formulated: H5: POS has significant positive influence on CA.

\subsubsection{Perceived Organizational Support and SCS}

Some researchers have pointed the role of supervisor support as a catalyst for career success to the detriment of colleagues' support, the perceived supervisor support consists on how employees evaluate the quality of relationships provided by the supervisors (Yang et al., 2015; Kurtessis et al., 2015). This kind of support is the most powerful source of social support (Kim et al., 2017) because these supervisors will take care of their subordinates and encourage them to face the challenging situations they may encounter. According to Karatepe and Olugbade (2017), the supervisor support plays an important role for the employees because a hierarchy must be attentive to the needs of their workers: motivate them to acquire new skills, ensure career development and encourage more exchange of opinions and ideas. Kurtessis et al. (2015) added that the decision-makers play a vital role as they are seen as the largest source of organizational support, providing rewards and both material and moral resources to employees. 
Thomas et al. (2005) concluded that career sponsorship, received from a senior level ennployee or a supervisor support, is a real predicator of CS. The same results were obtained by Yang and al. (2015), in their study on the category of aging workforce. They also claimed that the support of supervisors and colleagues influences differently because supervisors must take in account employees complaints and assist them to obtain necessary resources while, colleagues can properly finish work tasks and reduce stress and presenteeism. We thus find that supervisor support is more closely related to SCS than coworker support.

Based on what said previously, we assume in our paper that the support of supervisors and colleagues impacts differently on the gender. Career success can be qualified as a very subjective phenomenon in the sense that is related to individual perceptions of their work experiences.

Women's perception of CS is different than from that of men (Nabi, 2000). Men tends to employ peer and network support to evaluate their SCS, while women, generally sensitive (Gosh \& Foued, 2017), need more colleagues support to succeed in a stressful work situation where jobs become more and more diemanding. This can be understood from a cultural angle. Indeed, Hofsted (2017), who studied the impact of culture on the organizational behaviors, affirmed that Saudi Arabia is a collectivist culture which focuses on the group's attachment. This is reflected by the predominance of collective decisions in the organizations. Under high collectivism, an individual easily expresses his fear and stress to his colleagues since they are in the same bag. He feels safe in the group and returns his loyalty to them. More precisely, individual will be more comfortable when he shares his anxiety from career challenges with his colleagues rather than supervisor, who also have to evaluate his performance. The same fact is observed in the aging population also by Yang and al. (2015) who have stated that men feels more confident to scope the challenges with colleagues' helps. In regard to what is said above, we consider the POS as a factor that promotes SCS and we formulate the following hypothesis:

\section{H6: Perceived Organizational Support has significant positive influence on SCS.}

\subsubsection{CA as a Mediator between POS and SCS}

Our study aims to investigate the effects of CA as a mediator between POS and SCS. First, we showed above that CA positively impacts the SCS and Career Satisfaction is considered to be a result of CA (Karatepe \& Olugbade, 2017; Ployhart \& Bliese, 2006) while knowing that the CA includes four indicators (concern, confidence, control and curiosity) (Savickas \& Porfeli, 2012). We have demonstrated also that co-worker and supervisor support -the two facets of POS- are treated as resources activating CA (Yang et al., 2015; Karatepe \& Olugbade, 2017; Ito and Broheridge, 2005). Finally, we underlined that POS foster SCS (Kurtessis et al., 2015; Yang et al., 2015; Karatepe \& Olugbade, 2017; Ramosa \& Almeida, 2017). Consequently, the CA plays a mediating role between POS and SCS. Starting from this idea, the CA is considered as a set of abilities that will help individuals already supported by the hierarchy and colleagues to adapt to the new work situations in order to guarantee success. But this influence is partial because the notion of CA is very complex. In our knowledge, no previous study has evaluated the role of CA as a mediator between its predictors and SCS. We emit this following hypothesis:

\section{H7: POS indirectly influences $C S$ through the mediation of $C A$.}

The following figure reflects the conceptual model of our study.

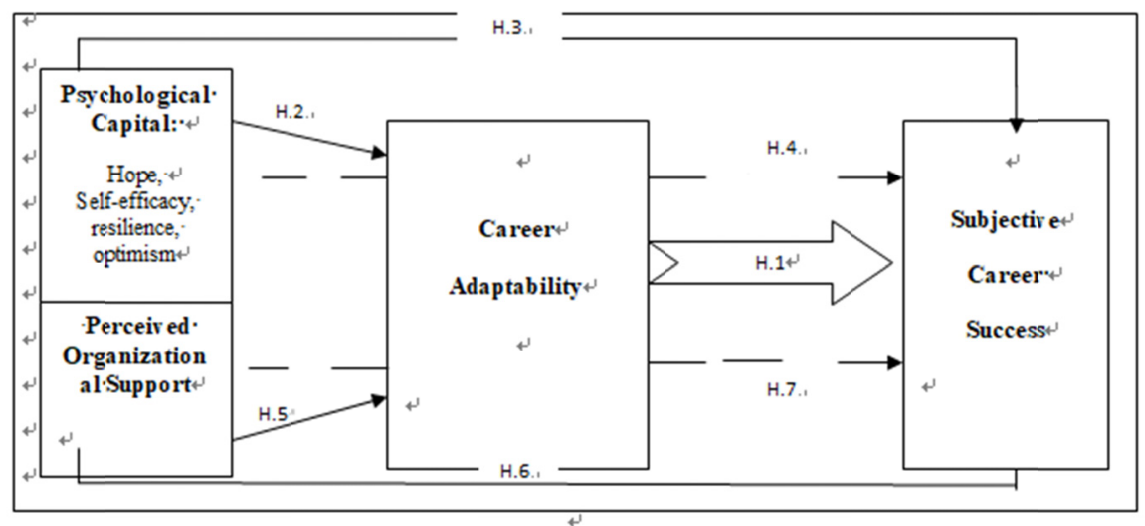

Figure 1. The conceptual model 


\section{Method \\ 4.1 Sample}

To test the study hypotheses, data were collected from women academic (teaching) staff working in five government and private universities in Riyadh, KSA. According to the Ministry of Education website, 6974 university teachers are women. A total of 400 questionnaires were distributed; of the 252 copies of them returned, 24 excluded due to incomplete answers, which gave a total of 228 effective copies were retrieved with a valid response rate of $57 \%$.

About $9.6 \%$ of the respondents were professors, $13.2 \%$ associate professors, $25.4 \%$ assistant professors, $32.1 \%$ were lecturers and $19.7 \%$ demonstrators. About $17.5 \%$ of the respondents were aged less than $30,53.5 \%$ between 30 and less than $40,23.7 \%$ between 40 and less than 50 and $5.3 \%$ older than 50 years old. Years of work at the university varied as follows: $14.9 \%$, under 5 years, $35.1 \%$ from 5 to less than 10 years, $37.7 \%$ from 10 to less than 20 years and the remaining percentage is 20 years and over.

\subsection{Procedure}

The first aim of this paper is to measure the effect of CA on SCS. The second aim is to see how PsyCap and POS first impact on CA and then SCS. Therefore, a questionnaire was prepared around CA, PsyCap, PO and SCS measurement scales. As these measurement scales were in English language while Saudi students' native language is Arabic, we used back-translation technique which has allowed us to translate items from original scales while preserving their meaning and avoiding translation errors as much as possible. The questionnaire was hand-transmitted for some colleagues and electronically for others.

\subsection{Measures}

In this paper, we used four different scales formed of items ranging from $1=$ strongly disagree to $5=$ strongly agree to measure PsyCap and POS, ranging from $1=$ very strong to $5=$ Not strong at all to measure CA and ranging from $1=$ Completely satisfied to $5=$ Not at all satisfied to measure SCS.

\subsubsection{CA}

The Career-Adapt-Abilities-Scale (CAAS) introduced by Savickas \& Porfeli (2012) contains 24 items is used to measure CA. The CAAS is comprised four subscales: concern, control, curiosity, and confidence. For example, items include: "Preparing for the future." (concern), "Doing what's right for me" (control), "Looking for opportunities to investigating options before making a choice" (curiosity) and "Learning new skills" (confidence).

\subsubsection{SCS}

The Subjective Career Success Inventory (SCSI) scale, proposed by Shockley (2015), is used to measure SCS. The SCSI contains 24 items explaining subjective career success. For example, "I am proud of the quality of the work I have produced. " and " My career is personally satisfying."

\subsubsection{PsyCap}

The Psychological Capital questionnaire, designed by Luthans et al. (2007) is used to measure the PsyCap. The four dimensions of PsyCap each include three items. Example items include optimism "In this job, things never work out the way want them to", resilience "I usually take stressful things at work in stride", hope "There are lots of ways around any problem" and self-efficacy "I feel confident helping to set targets/goals in my work area". In the literature, there are two ways to measure PsycCap. The first is to consider the PsycCap as an entity and measure the synergistic effect of the variables that ensues. The second possibility is to take these four components separately (Luthans et al., 2004; Luthans \& Youssef, 2004). In this paper, we will study these components one by one in order to obtain more conclusive results.

\subsubsection{POS}

The perceived organizational support (POS) scale (Haynes et al., 1999; Eisenberger et al., 2002) is used to measure POS. This scale is subdivided into two subscales: coworker support and supervisor support which each include 3 items. For example, on coworker support, the question is whether "coworkers help me with difficult tasks". On the supervisor support, respondents should answer to "My supervisor is helpful to me in getting the job done."

\subsection{Data Analysis}

To test measurement models, the proposed model and hypothesis data were analyzed using Confirmatory Factor Analysis (CFA) and Structural Equation Modeling (SEM )using the Amos (2016). Based on Garver and Mentzer (1999) recommendations, several Fit Index were undertaken to evaluate if the model fit of the measurement and structural models is globally accepted. Then, we used first the chi-square index which allowed the evaluation of 
our model and an estimation of the statistical significance of the difference between the model were $\left(\chi^{2}\right)$ values should be insignificant and the $(\chi 2 / \mathrm{df}(<2)$. In addition, we used Absolute Fit Index which confirm the quality of the matching of the measurement models, including Goodness of Fit Index (CFI $>0.9)$ and Root Mean Square Error of Approximation (RMSEA<0.08).

Furthermore, we used Incremental Fit Indexed which reflects the full acceptance of the model and includes Normed Fit Index (NFI), Comparative Fit Index (CFI), and Incremental Fit Index (IFI). For each of them, values greater than 0.90 are considered to indicate acceptable fit. We used also a Standardized Root Mean Square Residual (SRMR), the model fit assessment: SRMR $<.08$ is generally considered as a good fit. Finally, to test hypotheses we used Sobel test which allowed us to measure the significance of mediating effects (Kong et al., 2012)

\section{Results}

\subsection{Measurement Results}

To test the model which connecting CA and SCS, a CFA was conducted (cf. table1), shows that the models for measuring the four PsyCap components' (Optimism, Resilience, Self-Efficacy and Hope), POS, CA and SCS had adequate goodness-of-fit indices. All $\left(\chi^{2}\right)$ values are insignificant and the ratio between ( $\left.\chi 2 / \mathrm{df}\right)$ is less than two degree, indicating the acceptance of the model, as well as the, (RMSEA and SRMR $<0.08$, (CFI), (NFI) and (IFI) are high and close to one. These results confirm that the models are consistent with the sample data, assess the quality of the matching of the measurement models and indicate good model fit.

Table 1. Confirmatory Factor Analysis results

\begin{tabular}{|c|c|c|c|c|c|c|c|c|c|}
\hline Measures & $\chi^{2}$ & $\mathrm{df}$ & $\chi 2 \backslash \mathrm{df}$ & RMSEA & GFI & SRMR & NFI & CFI & IFI \\
\hline $\mathrm{CA}$ & 320.96 & 252 & 1.27 & 0.04 & 0.97 & 0.04 & 0.96 & 0.95 & 0.94 \\
\hline SCS & 401.52 & 252 & 1.59 & 0.05 & 0.99 & 0.03 & 0.94 & 0.98 & 0.95 \\
\hline Optimism & 16.12 & 9 & 1.79 & 0.04 & 0.96 & 0.05 & 0.97 & 0.99 & 0.95 \\
\hline Resilience & 12.32 & 9 & 1.37 & 0.06 & 0.98 & 0.05 & 0.94 & 0.96 & 0.98 \\
\hline Self-Efficacy & 11.68 & 9 & 1.30 & 0.05 & 0.96 & 0.04 & 0.95 & 0.96 & 0.96 \\
\hline Hope & 10.72 & 9 & 1.19 & 0.05 & 0.96 & 0.04 & 0.96 & 0.97 & 0.98 \\
\hline POS & 14.92 & 9 & 1.66 & 0.03 & 0.99 & 0.03 & 0.98 & 0.98 & 0.97 \\
\hline
\end{tabular}

Table 2 shows Descriptive Statistics, internal consistency (Cronbach's alpha) and correlations of study variables. The results regarding the reliability show that the Cronbach's alpha is ranged between (0.83 to 0.91$)$, this according to (Nunnaly and Bernstein, 1994) is an indication of internal consistency for all variables are satisfactory. As for the correlations between variables, (table 2 shows that all correlations are statistically positive and significant at $\mathrm{p}, 0.001)$.

Table 2. Descriptive statistics (Cronbach's $\alpha$ and Correlation matrix of the model variables)

\begin{tabular}{llllllllll}
\hline Measures & M & SD & 1 & 2 & 3 & 4 & 5 & 6 & 7 \\
\hline CA & 3.55 & 1.04 & $\mathbf{( 0 . 8 6 )}$ & & & & & & \\
SCS & 3.96 & 1.22 & 0.52 & $\mathbf{( 0 . 8 3 )}$ & & & & & \\
Optimism & 3.82 & 1.31 & 0.47 & 0.51 & $\mathbf{( 0 . 8 5 )}$ & & & & \\
Resilience & 3.96 & 0.78 & 0.36 & 0.42 & 0.39 & $\mathbf{( 0 . 8 1 )}$ & & & \\
Self-Efficacy & 4.02 & 1.11 & 0.32 & 0.37 & 0.38 & 0.53 & $\mathbf{( 0 . 9 1 )}$ & & \\
Hope & 4.11 & 1.34 & 0.29 & 0.34 & 0.32 & 0.45 & 0.41 & $\mathbf{( 0 . 8 8 )}$ & \\
POS & 3.44 & 0.81 & 0.35 & 0.31 & 0.29 & 0.48 & 0.57 & 0.34 & $\mathbf{( 0 . 8 9 )}$ \\
\hline
\end{tabular}

\subsection{Model Testing}

In order to test the mediating effects, we based on the comparison of alternative models provided by James et al. (2006). In our study, we tested two alternative models in order to determine which model better explains relationships among the study variable. 
The model (1): partially mediated model assumes that, in addition direct effects of PsyCap four components and POS on both CA and SCS, there is also an indirect impact of CA on the relationship between the four components of PsyCap, POS and SCS.

The model (2): fully-mediated model assumes that CA fully mediates the relationship between the four components of PsyCap, POS and SCS.

The result of this comparison between the two models, as shown in table 3, indicated that the partially mediated model has a better fit than the full mediated model. This result has been validated by Chi-square difference test which shows that the fit of the partial mediating model is better than of the fully mediating model ( $\chi^{2}$ is insignificant for only the partially mediating model). The ratio of $\chi 2 / \mathrm{df}$ is lower (2) for only the partial model. In addition, all the other Fit Index (RMSEA, SRMR, GFI, NFI, CFI and IFI) were better for partial mediation model compared to full mediation model. Consequently, the results of the partial mediation are used to evaluate the relationships in the proposed research model.

Table 3. Results of models' comparison

\begin{tabular}{|c|c|c|c|c|c|c|c|}
\hline Model & $\chi^{2}(\mathrm{df})$ & GFI & RMSEA & SRMR & NFI & CFI & IFI \\
\hline Full mediation & $\begin{array}{l}\chi^{2}(20)=102.54 \\
\mathrm{P}<0.001\end{array}$ & 0.94 & 0.15 & 0.09 & 0.89 & 0.92 & 0.93 \\
\hline Partial mediation & $\begin{array}{l}\chi^{2}(15)=23.56 \\
P<0.81\end{array}$ & 1.00 & 0.03 & 0.05 & 0.94 & 0.96 & 0.97 \\
\hline
\end{tabular}

\subsection{Direct and Indirect Effects}

To test hypothesis, the values of standardized regression weights (table 4 and fig. 2) revealed that each of the four PsyCap components and particularly Optimism affect directly and positively both CA and SCS. Thus, H.1, H.2, H.3, H.4 and H.5 were fully supported. Furthermore, the results showed that all standardized indirect effects are significant. Consequently, H.6 and H.7 which assumed partial mediation of CA are supported.

Otherwise, two indirect effects deserved to be mentioned. First, the PsyCap components: optimism, resilience, self-efficacy and hope impact respectively $44 \%, 46 \%, 52 \%$ and $51 \%$ of the total effect on SCS through the CA. Second, POS effects $58 \%$ of the total effect on SCS through CA.

Table 4: Standardized direct, indirect and total effects for the hypothesized partial mediation model

\begin{tabular}{|c|c|c|c|c|}
\hline \multirow[t]{2}{*}{ Predictor } & \multicolumn{2}{|c|}{ Direct effect } & \multirow{2}{*}{$\begin{array}{l}\text { Indirect effect } \\
\text { SCS }\end{array}$} & \multirow{2}{*}{$\begin{array}{l}\text { Total effec } \\
\text { SCS }\end{array}$} \\
\hline & $\mathrm{CA}$ & SCS & & \\
\hline Optimism & 0.26 & 0.19 & $0.15 * *$ & 0.34 \\
\hline Resilience & 0.22 & 0.15 & $0.13 * *$ & 0.28 \\
\hline Self-efficacy & 0.24 & 0.13 & $0.14 * *$ & 0.27 \\
\hline Hope & 0.31 & 0.17 & $0.18 * *$ & 0.35 \\
\hline Perceived organizational support & 0.32 & 0.14 & $0.19 * *$ & 0.33 \\
\hline Career Adaptability & - & 0.59 & - & 0.59 \\
\hline
\end{tabular}

Notes. Sobel tests were computed for the indirect effects; **for ps, 0.01 


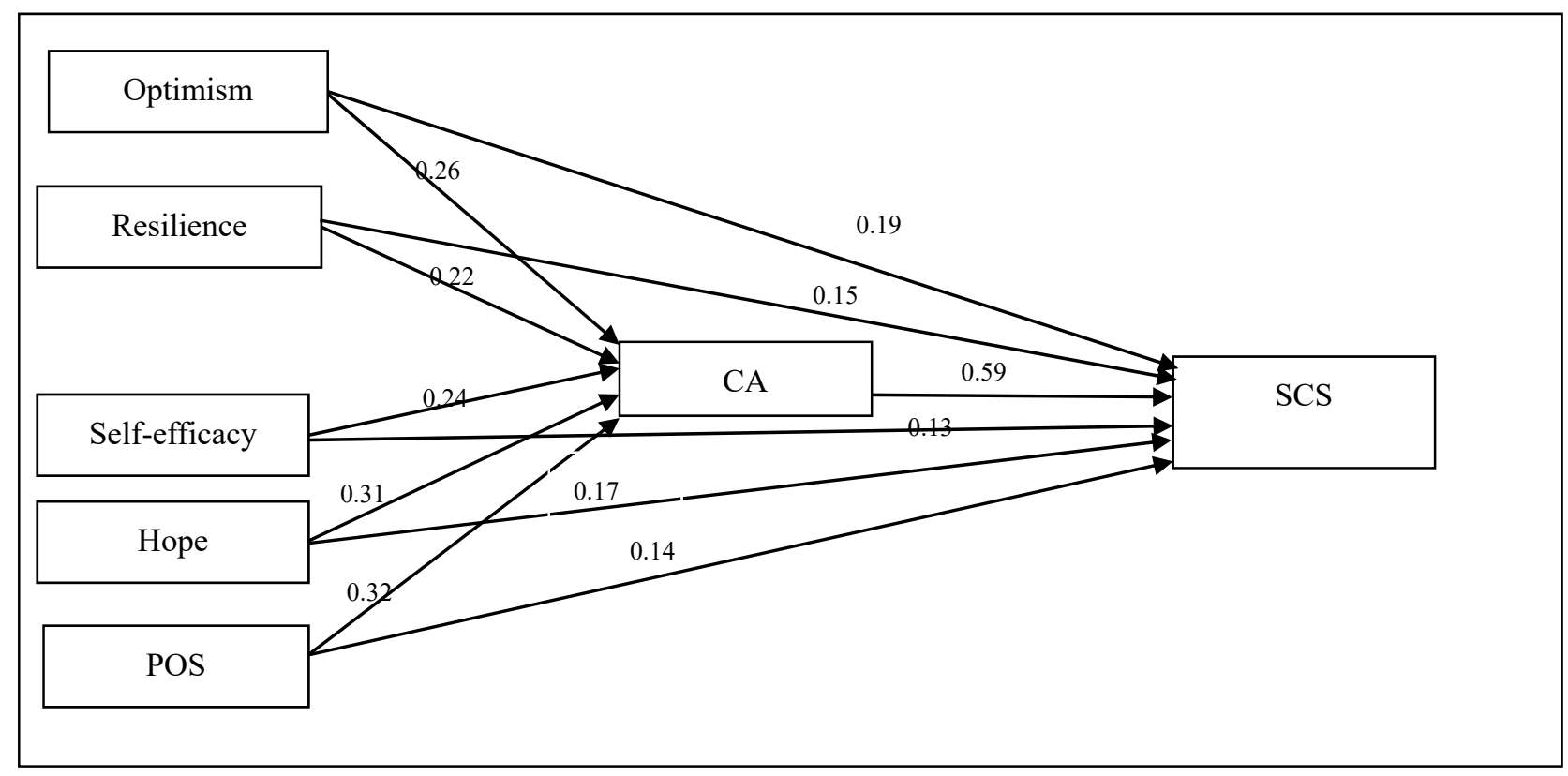

Figure 2. Path standardized regression weights for the model

\section{Discussion}

The past few years have witnessed growing academic interest in studying the factors that increase employees' $\mathrm{CA}$ and success. The current study takes a further step to provide a new understanding of the relationship between CA and SCS for women in general and Saudi women in particular. This paper seeks to determine the impact of both PsyCap components and POS on CA and SCS. In addition, this paper aims to examine the mediating role of CA in the relationship between PsyCap, POS and SCS. The empirical study has enabled us to access to important results.

First of all, as we expected, the results of H.1 study found that CA has a positive impact on SCS. These findings converge with Career Construction Theory (CCT) of Savickas (2005), which confirmed that continuous adaptation to the work environment is crucial to achieve career success. These results are supported also by previous empirical research which highlighted that CA is related positively to important work and career outcomes specially job and career satisfaction (Chan \& Mai, 2015; Zacher and Griffin, 2015). Then, we can affirm that the CA must be perceived as an important variable to predict SCS (Zacher, 2014). Another possible interpretation linked to the same result may be mentioned: employees with a high level of CA have more skills and more psychosocial resources that allow them to adapt to the future demands of their profession. More explicitly, these employees must be more prepared for future tasks and challenges by exploring possible selves and future scenarios and transform their goals into reality in order to solve problems successfully and overcome obstacles. These, in turn, have a positive impact on their professional success.

Secondly, the results of current study underscore the positive impact of PsyCap components on both CA and SCS. Buyukgoze-Kavas (2016) got the same results and noted that only hope, resilience and optimism have positive effects and predict CA, while our finding showed that self-efficacy (the fourth component of PsyCap) has also positive effects and predicts CA. Other previous studies have reached the same results and confirm the positive effect of PsyCap components on SCS (Cenciotti et al 2017; Luthans et al., 2010; Kaplan and Bíckes, 2013). Then, we can advance that CA encourages the willingness to deal with new or unknown situations and requires a positive PsyCap resources to reinforce the ability of people who meet challenges. Indeed, workers with more Self-efficacy are more likely to engage in risky and challenging activities (Bandura, 1997). Hopeful individuals can set higher goals for their career and push themselves to act more proactively to achieve their objectives. High Optimism people build expectations in areas that stimulate the pursuit of their goal and deal with it (Carver \& Scheier, 2002). Resilient individuals are those who recover from failure and pursue proactive professional behaviors even after a failed experience. Therefore, an employee with high PsyCap has the ability to adapt professionally and achieve professional success as well.

Thirdly, the results of the hypotheses testing the positive impact of POS converge with the literature which confirms the existence of a positive effect of POS on both CA and SCS. Our results are consistent with the results 
of previous studies (Karatepe and Olugbade, 2017; Ito and Brotheridge, 2005; Hirschi, 2014) and confirm that POS has obviously positive impact on CA. The existence of effective social support in the workplace helps employees to be well prepared for the future and to achieve their career goals (concern). This social support also allows employees to make decisions with autonomy (control). Finally, the presence of such support allows employees to consider future scenarios related to career (curiosity) and help them to overcome obstacles (confidence).

Otherwise, our results also are consistent with Alzyoud (2017) and Liu et al. (2015) that the POS is one of the key predictors of career success. In particularly, when employees work in a supportive environment, including support from coworkers and supervisors, they are able to manage better work-related issues and get feedback on their work and performance. Moreover, employee will be helped especially by supervisors to develop their career plans and improve their skills and abilities. Consequently, POS will increase their ability to achieve adaptation and success in their careers.

Finally, the results concluded that CA plays partial mediating role between PsyCap (hope, self-efficacy, resilience, and optimism) and SCS. These mediation hypotheses are supported by prior researches confirming that CA can be considered as a mediating variable that strengthens the influence of many factors on organizational and individual outcomes. For example, results of Maggiori et al.'s (2013) study reached that CA had a partial mediating role in the relationship between professional context and general and professional well-being. In another perspective, some authors emphasized the mediating role of CA in the relationship between work social support and career satisfaction and turnover intentions (Karatepe and Olugbade, 2017; Han and Rojewski, 2015). While Nilforooshan and Salimi (2016) pointed out the relationship between specific personality dimensions and career engagement which are mediating by CA.

\section{Theoretical and Practical Implications}

\subsection{Theoretical Implications}

The choice of our sample, which is of Saudi university's professors, led us to very important results. Moreover, this field of observation has not been sufficiently exploited despite abundant literature on AC.

Otherwise, by relying on a panoply of theoretical perspectives we have discovered that some relationships, concerning the links between the variables that we have selected for this paper, are undefined. We tried to counter this limit by opting for an in-depth approach to collect information related to cognitive psychology that allowed to apprehend the perception that women have of their career. Concretely, we have linked new factors, such as the PsyCap and POS, determining both the AC and SCS.

Finally, the study clearly underlines that there is a close relationship between CA and SCS and that the women's CA is more delicate than men's CA as long as she has to deal with several paradoxes at the same time. The striking in this study is that, despite the social and cultural constraints, woman university teacher has a positive PsyCap that helps to progress in her career and encounter these obstacles. For example, the more the woman is confident, resilient with self-efficacy and optimizes the future, the more she will expend effort to overcome challenges and then will positively perceive her career results.

\subsection{Practical Implications}

Interesting insights revealed in our study are useful for universities, teachers and management. If taken in consideration, they are likely to improve the behavior of the decision-makers with respect to the teaching staff.

First of all, it seems important to focus on positive personal attitudes as a sine-qua-non-condition for ensuring AC and SCS thereafter. We have emphasized above that jobs are constantly evolving and frustrating women and therefore, it is necessary for policy makers to focus more on the development of positive attitudes and adopt new person-centered approaches per instance coaching as a way of developing the PsyCap (the four dimensions) to adapt carefully their career first and to ensure both her personal and professional balance. However, conventional approaches such as training are insufficient in view of new job requirements and organizational performance since they can be perceived as a sanction and create a feeling of discomfort and stress.

Secondly, CA also depends on the perception that teachers have of their careers. In fact, the more positive is this perception, the more teachers will persevere in their career and develop positive attitudes to reach new achievements. This is why decision-makers must consider women's career challenges and identify their scientific contributions even if they are minor, and value them to maintain a required level of motivation. The results of our study revealed that women's AC cannot be immediate due multiple challenges despite the psyco-cognitive abilities that they possess and the Organizational Support that they can benefit. Women must then manage their careers in a 
rational way by avoiding the underestimation and ambitions excess. Such posture will guarantee a better adaptability and positive image of their achievements.

Thirdly, in addition to the main findings, this study brings up other important information likely to interest more decision-makers. We emphasized on the importance of the healthy environment, requiring supportive relationship between the different levels at university, necessary for teacher's professional development. Thus, creating a supportive environment requires from management to plan specific training for decision-makers who will exploit CA's resources of each employee to manage individuals' career efficiently. The need of Organizational Support does not in any way call into question her/his autonomy, on contrary, it's a proof that university teacher has a sense of sharing with her/his entourage and possesses emotional and cognitive capacities allowing her/him to move with precaution and serenity in her/his career.

Finally, the achievement of the SCS must be part of a win-win strategy: University and academic staff must work together to ensure that everyone achieves the desired performance. By offering a supportive framework based on social support and participation in decision-making, the university guarantees teachers' motivation and involvement. In return, teacher will feel secure, efficient and invest more in skills and abilities in order to reach the SSC.

\section{Limitations and Future Research Suggestions}

Our research is of course not without limitations. The first limit is related to sampling method. Indeed, we chose to conduct this research in Saudi universities which are a fertile ground as long as they can be considered as a multinational organization putting in competition several teachers belonging to different cultures. Then, the influence of organizational culture on careers is significant and should be studied (Centiotti et al. 2016) however, our sample involves only of Saudi teachers. This limit can be mitigated by adopting a comparative cultural approach in order to obtain more consistent results.

The second limit is the generality of results due to the fact that we have linked in this study all the components of each principal variable including PsycCap, POS and CA. A components' selection of each scale with more significant impacts on the SC could allow us to advance more targeted results.

Finally, the scale measure validity used in this research can be questioned. In our study, we investigated a teaching university job which is in continuous evolution. But, the Savicaks scale (2005) aims to study the CA of individuals only at the present. That's why; it would be rise to add questions engaging the future. Moreover, the items of the POS and SCS measurements involve also in the very short term, which makes it is possible to highlighting the opinions and perceptions of the interviewees on the variables studied at present only. Due to the evolution of the working conditions and their goals, the responses are likely to change in the future; it would be wise then to adopt a longitudinal study apprehending the behavior of women's jobs.

\section{Conclusion}

In closing, we want to bring to the reader attention that the obtained results highlight the progress made by Saudi women in the field of work and particularly at the university. Despite their recent entry into the academic world, Saudi women are taking advantage of the opportunities offered by a promising job market that requires the recruitment of high-level graduated to deal with demanding environment. Not to mention the moral and material support that they benefit from the state, their organizations and even their families. Such opportunities give them the ability to work with autonomy in order to ensure professional adaptation and achieve the expected success.

\section{References}

Alzyoud, A. (2017). The Predictors of Career Success, International Review of Management and Marketing, 7(2), 22-26.

Avey, J. B., Nimnicht J. L., \& Pigeon, N. G. (2010). Two field studies examining the association between positive psychological capital and employee performance. Leadership \& Organization Development Journal, 31(5), 384-401. https://doi.org/10.1108/01437731011056425

Bandura, A. (1997). Self-efficacy: The exercise of control. New York: Freeman.

Barrera, M., Jr., Sandler, I. N. and Ramsay, T. B. (1981). Preliminary development of a scale of social support: Studies on college students. American Journal of Community Psychology, 9, 435-447. https://doi.org/10.1007/BF00918174

Bocciardi, F., Caputo, A., Fregonese, C., Langher, V., \& Sartori, R. (2017). Career adaptability as a strategic competence for career development: An exploratory study of its key predictors. European Journal of Training and Development, 41(1), 67-82. https://doi.org/10.1108/EJTD-07-2016-0049 
Bombuwela, P. M., \& De Alwis, A. C. (2013). Effects of Glass Ceiling on Women Career Development in Private Sector Organizations- Case of Sri Lanka, Journal of Competitiveness, 5(2), 3-19. https://doi.org/10.7441/joc.2013.02.01

Buyukgoze-Kavas, A. (2016). Predicting Career Adaptability from Positive Psychological Traits. The Career Development Quarterly, 64, 115-125. https://doi.org/10.1002/cdq.12045

Carver, C. S., \& Scheier, M. F. (2002). Optimism. In C. R. Snyder \& S. Lopez (Eds.), Handbook of Positive Psychology (pp. 231- 243). Oxford, England: Oxford University Press.

Cenciotti, R., Alessandri, G., \& Borgogni, L. (2016). Psychological Capital and Career Success Over Time: The Mediating Role of Job Crafting. Journal of Leadership \& Organizational Studies, 24(3), 372-384. https://doi.org/10.1037/t65741-000

Chan, S. H. J., \& Mai, X. (2015). The relation of career adaptability to satisfaction and turnover intentions. Journal of Vocational Behavior, 89, 130-139. https://doi.org/10.1016/j.jvb.2015.05.005

Chen, H. (2013). The relationship between psychological capital and proactive career behavior of Chinese white collar workers in their early career. Retrieved from http:/hrmstudy.com/wp-content/uploads/2015/02/Chen2013.pdf

Chong, S. H., \& Leong F. T. L. (2017). Antecedents of Career Adaptability in Strategic Career Management. Journal of Career Assessment, 25(2), 268-280. https://doi.org/10.1177/1069072715621522

Clapp-Smith, R., Vogelgesang, G. R., \& Avey J. B. (2009). Authentic leadership and positive psychological capital: The mediating role of trust at the group level of analysis. Journal of Leadership \&Organizational Studies, 15(3), 227-240. https://doi.org/10.1177/1548051808326596

Coetzee, M., Ferreira, N. and Shunmugum, C. (2017). Psychological career resources, career adaptability and work engagement of generational cohorts in the media industry. SA Journal of Human Resource Management, SA Tydskrif vir Menslikehulpbronbestuur, 15, 868. https://doi. org/10.4102/sajhrm. v15i0.868

Coutu, D. L. (2002). How resilience works. Harvard Business Review, 80(5), 46-55.

Eisenberger, R., Huntington, R., Hutchison, S., \& Sowa, D. (1986). Does pay for performance increase or decrease perceived self-determination and intrinsic motivation? Journal of Personality and Social Psychology, 77, 1026-1040. http://psycnet.apa.org/doi/10.1037/0022-3514.77.5.1026

Eisenberger, R., Stinglhamber, F., Vandenberghe, C., Sucharski, I., \& Rhoades, L. (2002). Perceived supervisor support: Contributions to perceived organizational support and employee retention. Journal of Applied Psychology, 87, 565-573. https://doi.org/10.1037//0021-9010.87.3.565

Ferreira, N. (2012). Constructing a psychological career profile for staff retention. Doctoral Thesis. Pretoria, South Africa: University of South Africa.

Garver, M. S., \& Mentzer, J. T. (1999). Logistics research methods: employing structural equation modelling to test for construct validity, Journal of Business Logistics, 20(1), 33-57.

Ghosh, A., \& Fouad, N. A. (2017). Career Adaptability and Social Support Among Graduating College Seniors. The Career Development Quarterly, 70, 278-283. https://doi.org/10.1002/cdq.12098

Guan, Y., Guo, M. H., Bond, Z., Cai, X., Zhou, J., \& Wang, Y. (2014). New job market entrants' future work self, career adaptability and job search outcomes: Examining mediating and moderating models. Journal of Vocational Behavior, 85,136 -145. https://doi.org/10.1016/j.jvb.2014.05.003

Hall, D. T., \& Chandler, D. E. (2005). Psychological success: When the career is a calling. Journal of Organizational Behaviour, 26, 155-176. https://doi.org/10.1002/job.301

Hämmig, O. (2017). Health and well-being at work: The key role of supervisor support. SSM - Population Health, 3, 393-402. https://doi.org/10.1016/j.ssmph.2017.04.002

Han, H., \& Rojewski, J. W. (2015). Gender- Specific Models of Work-Bound Korean Adolescents' Social Supports and Career Adaptability on Subsequent Job Satisfaction. Journal of Career Development, 42(2), 149-164. https://doi.org/10.1177/0894845314545786

Haynes, C. E., Wall, T. D., Bolden, R. I., Stride, C., \& Rick, J. E. (1999). Measures of perceived work characteristics for health services research: Test of a measurement model and normative data. British Journal of Health Psychology, 4, 257-275. https://doi.org/10.1348/135910799168614

Hirschi, A., (2014). Hope as a resource for self-directed career management: Investigating mediating effects on 
proactive career behaviors, life and job satisfaction. Journal of Happiness Studies, 15(6), 1495-1512. Springer https://doi.org/10.1007/s10902-013-9488-x

Hofstede, G. (2017). The Hofstede Insights: Saudi Arabia. Retrieved from https://www.hofstede-insights.com/country/saudi-arabia/

Ismail, S., Ferreira, N., \& Coetzee, M. (2016). Young emerging adults' graduateness and career adaptability: Exploring the moderating role of self-esteem. Journal of Psychology in Africa, 26(1), 1-10. https://doi/10.1080/14330237.2016.1148417

Ito, J. K., \& Brotheridge, B. M. (2005). Does supporting employees' career adaptability lead to commitment, turnover, or both? Human Resource Management, 44(1), 5-19. https://doi.org/10.1002/hrm.20037

James, L. R., Mulaik, S. A., \& Brett, J. M. (2006). A tale of two methods. Organizational Research Methods, 9(2), 233-244. http://dx.doi.org/10.1177/1094428105285144

Jiang, Z., Hub, X., \& Wang, Z. (2018). Career adaptability and plateaus: The moderating effects of tenure and job self-efficacy. Journal of Vocational Behavior, (104), 59-71. https://doi.org/10.1016/j.jvb.2017.10.006

Kaplan, M., \& Biçkes, D. (2013). The Relationship Between Psychological Capital and Job Satisfaction: A Study of Hotel Businesses in Nevşehir. Yönetim Ve Ekonomi, 20(2), 233-242

Karatepe, O. M., \& Olugbade, O. A. (2017). The effects of work social support and career adaptability on career satisfaction and turnover intentions. Journal of Management \& Organization, 23(3), 337-355. https://doi.org/10.1017/jmo.2016.12

Kim, H. J., Hur W. M., Moon T. W., \& Jun J. K. (2017). Is all support equal? The moderating effects of supervisor, coworker, and organizational support on the link between emotional labor and job performance. $B R Q$ Business Research Quarterly, 20(2), 124-136. https://doi.org/10.1016/j.brq.2016.11.002

Klehe, U.-C., Zikic, J., Van Vianen, A. E. M., \& De Pater, I. E. (2011). Career adaptability, turnover and loyalty during organizational downsizing. Journal of Vocational Behavior, 79, 217-229. https://doi.org/10.1016/j.jvb.2011.01.004

Koen, J., Klehe, U. C., \& Van Vianen, A. E. (2012). Training career adaptability to facilitate a successful school-to-work transition. Journal of Vocational Behavior, 81, 395-408. https://doi.org/10.1016/j.jvb.2012.10.003

Kurtessis, J. N., Eisenberger, R., Ford, M. T., Buffardi, L., Stewart, K. A., \& Adis, C. S. (2015). Perceived organizational support: A meta-analytic evaluation of organizational support theory. Journal of Management. https://doi.org/10.1177/0149206315575554

LaRocco J. M., Tetrick L. E., \& Meder D. (1989). Differences in perceptions of work environment conditions, job attitudes, and health beliefs among military physicians, dentists, and nurses. Military Psychology, 1(3) 135-151. https://doi.org/10.1207/s15327876mp0103_2

Larson, M., \& Luthans, F. (2006). Potential added value of psychological capital in predicting work attitudes. Journal of Leadership and Organizational Studies, 13(1), 44-61. https://doi.org/10.1177/10717919070130010701

Levene, R. A. (2015). Positive Psychology At Work: Psychological Capital and Thriving as Pathways to Employee Engagement. Master of Applied Positive Psychology (MAPP) Capstone Projects.

Liu, J., Yang, J., Yang, Y., \& Liu, Y. (2015). The relationships among perceived organizational support, intention to remain, career success and self-esteem in Chinese male nurses, International Journal of Nursing Sciences, 2(4), 389-393. https://doi.org/10.1016/j.ijnss.2015.01.004

Luthans F., \& Youssef, C. M. (2004). Human, social, and now positive psychological capital management. Organizational Dynamics, 33(2), 143-160. https://doi.org/10.1016/j.orgdyn.2004.01.003

Luthans F., \& Youssef, C. M. (2007). Emerging positive organizational behavior. Journal of Management, 33(3), 321-349. https://doi.org/10.1177/0149206307300814

Luthans, F. (2002). Positive organizational behavior: Developing and managing psychological strengths. Academy of Management Executive, 16(1), 57-72. https://doi.org/10.5465/ame.2002.6640181

Luthans, F., Avey, J. B., Avolio, B. J., and Peterson, S. J. (2010). The Development and Resulting Performance Impact of Positive Psychological Capital. Articles Human Resource Development Quarterly, 21(1), 41-67. https://doi.org/10.1002/hrdq.20034 
Luthans, F., Avolio, B. J., Avey, J. B., \& Norman, S. M. (2007). Positive psychological capital: measurement and relationship with performance and satisfaction. Personnel psychology, 60(3), 541-572. https://doi.org/10.1111/j.1744-6570.2007.00083.x

Luthans, F., Luthans, K., \& Luthans, B. (2004). Positive psychological capital: Beyond the human and social capital. Business Horizons, 47(1), 45-50. https://doi.org/10.1016/j.bushor.2003.11.007

Luthans, F., Norman, S. M., Avolio, B. J., \& Avey, J. B. (2008). The mediating role of psychological capital in the supportive organizational climate - employee performance relationship. Journal of Organizational Behavior, 29(2), 219-238. https://doi.org/10.1002/job.507

Maggiori, C., Johnston, C. S., Krings, F., Massoudi, K., \& Rossier, J. (2013). The role of career adaptability and work conditions on general and professional well-being. Journal of Vocational Behavior, 83(3), 437-449. https://doi.org/10.1016/j.jvb.2013.07.001

McMahon, M., Watson, M., \& Bimrose, J. (2012). Career Adaptability: A Qualitative Understanding from the Stories of Older Women. Journal of Vocational Behavior, 80(3), 762-768. https://doi.org/10.1016/j.jvb.2012.01.016

Nabi, G. R. (2000). Motivational attributes and organizational experiences as predictors of career-enhancing strategies. Career Development International, 5(2), 91-98. https://doi.org/10.1108/13620430010318963

Nilforooshan, P., \& Salimi, S. (2016). Career adaptability as a mediator between personality and career engagement. Journal of Vocational Behavior, 94, 1-10. https://doi.org/10.1016/j.jvb.2016.02.010

Norman, S. M. (2006) The role of trust: implications for psychological capital and authentic leadership. Unpublished PhD Dissertation. The Graduate College at the University of Nebraska, Lincoln, NE.

Nunnally, J. C., \& Bernstein, I. H. (1994). Psychometric Theory. (3rd ed.). New York: McGraw-Hill.

Öncel, L. (2014). Career Adapt-Abilities Scale: Convergent validity of subscale scores. Journal of Vocational Behavior, 85, 13-17. https://doi.org/10.1016/j.jvb.2014.03.006

Pan, J. and Zhou, W. (2015). How Do Employees Construe Their Career Success: An improved measure of subjective career success? International Journal of Selection and Assessment, 23(1), 45-58. https://doi.org/10.1111/ijsa.12094

Peterson, S., Luthans, M., Avolio, B. Walumbwa, F., \& Zhang, Z. (2011). Psychological capital and employee performance: a latent growth modelling approach, Pers. Psychol., 64(2), 427-450. https://doi.org/10.1111/j.1744-6570.2011.01215.x

Pierce, G. R., Sarason, I. G. and Sarason, B. R. (1996). Coping and social support. In M. Zeidner \& N. S. (Eds.), Handbook of coping: Theory, research, applications (pp. 434-451). Canada: John Wiley \& Sons.

Pigeyre, F., \& Valette, A. (2004). Les carrières des femmes à l'université. "les palmes de verre du cocotier". Revue française de gestion, 30(151), 173-189. https://doi.org/10.3166/rfg.151.173-190

Ployhart, R. E., \& Bliese, P. D. (2006). Individual adaptability (I-ADAPT) theory: Conceptualizing the antecedents, consequences, and measurement of individual differences in adaptability. Amsterdam, Netherland: Elsevier. http://doi.org/10.1016/S1479-3601(05)06001-7

Ramosa, O., \& Almeida, H. (2017). Work engagement, social support, and job satisfaction in Portuguese nursing staff: A winning combination. Applied Nursing Research, 36, 37-41. https://doi.org/10.1016/j.apnr.2017.05.012

Rudolph, C. W., Lavigne, K. N., Katz, I. M., \& Zacher, H. (2017). Linking dimensions of career adaptability to adaptation results: A meta-analysis. Journal of Vocational Behavior, 102, 151-173. https://doi.org/10.1016/j.jvb.2017.06.003

Saks, A. M., \& Gruman, J. A. (2011). Organizational socialization and positive organizational behavior: Implications for theory, research, and practice. Canadian Journal of Administrative Sciences, 28(1), 14-26. https://doi.org/10.1002/cjas.169

Sarwar, H., Nadeem, K., \& Aftab, A. (2017). The impact of psychological capital on project success mediating role of emotional intelligence in construction organizations of Pakistan. Journal of Global Entrepreneurship Research, 7(22), 1-13. https://doi.org/10.1186/s40497-017-0080-4

Savickas, M. L. (1997). Career adaptability: An integrative construct for life-span, life-space theory. The Career Development Quarterly, 45(3), 247-259. https://doi.org/10.1002/j.2161-0045.1997.tb00469.x 
Savickas, M. L. (2005). The theory and practice of career construction. In S. D. Brown \& R. W. Lent (Eds.), Career development and counseling: Putting theory and research to work (pp. 42-70). Hoboken, NJ: John Wiley \& Sons.

Savickas, M. L. (2012). Life design: A paradigm for career intervention in the 21 st century. Journal of Counseling and Development, 90(1), 13-19. https://doi. org/10.1111/j.1556-6676.2012.00002.x

Savickas, M. L. (2013). Career construction theory and practice. In R. W. Lent \& S. D. Brown (Eds.), Career development and counseling: Putting theory and research to work (2nd ed., pp. 147-183). Hoboken, New Jersey: John Wiley \& Sons.

Savickas, M. L., \& Porfeli, E. J. (2012). Career Adapt-Abilities Scale: Construction, reliability, and measurement equivalence across 13 countries. Journal of Vocational Behavior, 80(3), 661-673. https://doi.org/10.1016/j.jvb.2012.01.011

Seligman, M. E. (2002). Authentic Happiness. New York, NY: Atria.

Shockley, K. M., Ureksoy, H., \& Rodopman, O. B. (2015) Development of a New Scale to Measure Subjective Career Success: A Mixed-Methods Study. Journal of Organizational Behavior, 37, 128-153. http://dx.doi.org/10.1002/job.2046

Singhal, H., \& Rastogi, R. (2018). Psychological capital and career commitment: the mediating effect of subjective well-being, Management Decision, 56(2), 458-473. https://doi.org/10.1108/md-06-2017-0579

Snyder, C. R. (2002). Hope theory: Rainbows in the mind. Psychological Inquiry, 13(4), $249-275$. https://doi.org/10.1207/s15327965pli1304_01

Snyder, C. R., \& Lopez, S. (Eds.). (2002). Handbook of positive psychology. New York: Oxford University Press

Spurk, D., Volmer, J., Hagmaier, T., \& Kauffeld, S. (2013). Why are proactive people more successful in their careers? The role of career adaptability in explaining multiple career success criteria. In E. E. Crossman and M. A. Weiler (Eds.), Personality traits: Causes, conceptualizations, and consequences (pp. 27-48). New York, NY: Nova Publishers.

Super, D. E., \& Knasel, E. G. (1981). Career development in adulthood: Some theoretical problems. British Journal of Guidance and Counseling, 9(2), 194-201. https://doi.org/10.1080/03069888100760211

Thomas, W. H. Ng., Lillian, T. E., Kelly, L. S., \& Daniel C. F. (2005). Predictors Of Objective and subjective career success: a meta-analysis. Personnel Psychology, $467-408$. https://doi.org/10.1111/j.1744-6570.2005.00515.x

Tlaiss, H. (2015). Neither-nor: career success of women in an Arab Middle Eastern context. Employee Relations, 37(5), 525-546. https://doi.org/10.1108/er-03-2014-0028

Tolentino, L. R., Sedoglavich, V., Lu, V. N., Garcia, P. R., \& Restubog, S. L. (2014). The role of career adaptability in predicting entrepreneurial intentions: A moderated mediation model. Journal of Vocational Behavior, 85(3), 403-412. https://doi.org/10.1016/j.jvb.2014.09.002

Tremblay, M., Dahan, J., \& Gianecchini, M. (2009). Le succès en carrière et la satisfaction: étude de l'influence des critères de promotion et des ancres de carrière auprès d'une population d'ingénieurs. AGRH.

Tremblay, M., Dahan, J., \& Gianecchini, M. (2014). The mediating influence of career success in relationship between career mobility criteria, career anchors and satisfaction with organization. Personnel Review, 43(6), 818-844. https://doi.org/10.1108/pr-08-2012-0138

Yang, W., Guan, Y., Lai, X., She, Z., \& Lockwood, A. J. (2015). Career adaptability and perceived overqualification: Testing a dual-path model among Chinese human resource management professionals. Journal of Vocational Behavior, 90, 154-162. https://doi.org/10.1016/j.jvb.2015.08.007

Zacher, H. (2014). Career adaptability predicts subjective career success above and beyond personality traits and core self-evaluations. Journal of Vocational Behavior, 84, 21-30. https://doi.org/10.1016/j.jvb.2013.10.002

Zacher, H. (2015). Daily manifestations of career adaptability: relationships with job and career outcomes. Journal of Vocational Behavior, 91, 76-86. https://doi.org/10.1016/j.jvb.2015.09.003

Zacher, H., \& Griffin, B. (2015). Older workers' age as a moderator of the relationship between career adaptability and job satisfaction. Work, Aging and Retirement, 1(2), 227-236. https://doi.org/10.1093/worker/wau009

Zhou, W., Sun, J., Guan, Y., Li, Y., \& Pan, J. (2013). Criteria of career success among Chinese employees: Developing a multidimensional scale with qualitative and quantitative approaches. Journal of Career 
Assessment, 21, 265-277. https://doi.org/10.1177/1069072712471302

\section{Copyrights}

Copyright for this article is retained by the author(s), with first publication rights granted to the journal.

This is an open-access article distributed under the terms and conditions of the Creative Commons Attribution license (http://creativecommons.org/licenses/by/4.0/). 